\title{
POINT-COUNTERPOINT
}

\section{Basic Biomedical Sciences and the Future of Medical Education: Implications for Internal Medicine}

\author{
Eric P. Brass, MD, PhD \\ Department of Medicine, Harbor-UCLA Medical Center and the David Geffen School of Medicine at UCLA, Torrance, CA, USA.
}

The academic model of medical education in the United States is facing substantial challenges. Apprenticeship experiences with clinical faculty are increasingly important in most medical schools and residency programs. This trend threatens to separate clinical education from the scientific foundations of medical practice. Paradoxically, this devaluation of biomedical science is occurring as the ability to use new discoveries to rationalize clinical decision making is rapidly expanding. Understanding the scientific foundations of medical practice and the ability to apply them in the care of patients separates the physician from other health care professionals. The de-emphasis of biomedical science in medical education poses particular dangers for the future of internal medicine as the satisfaction derived from the application of science to the solving of a clinical problem has been a central attraction of the specialty. Internists should be engaged in the ongoing discussions of medical education reform and provide a strong voice in support of rigorous scientific training for the profession.

KEY WORDS: biomedial sciences; medical education; internal medicine; apprenticeship.

J Gen Intern Med 24(11):1251-4

DOI: $10.1007 / \mathrm{s} 11606-009-0998-5$

(C) Society of General Internal Medicine 2009

$\mathrm{T}$ he Carnegie Foundation's Report on Medical Education in the United States and Canada, commonly referred to as the Flexner Report ${ }^{1}$, noted in 1910 that "Society reaps at this moment but a small fraction of the advantage which current knowledge has the power to confer". The report also emphasized that "modern medicine...is...more than mere empiricism". These assessments hold true today as our understanding of human biology and disease has reached a depth and richness unimaginable a few decades ago. Yet, contemporary trends threaten to undermine the fundamental tenets of medical education that have been widely embraced throughout most of the 20th Century.

The Flexner Report emphasized an academic training model in favor of the less well standardized apprenticeship model which dominated 100 years ago in the United States ${ }^{1,2}$. This academic model links the scientific principles underlying human biology and disease to the clinical decision making

Received September 30, 2008

Revised February 25, 2009

Accepted April 1, 2009 that is central to effective medical practice. The academic clinician who is able to apply fundamental scientific principles to sound clinical reasoning is central to this model. This educational model is implicitly based on the unproven hypothesis that medical decision making based on an understanding of the underlying biomedical sciences results in improved clinical care. However, no alternatives to the current model have been shown superior, the core model has served society well, and the principles are inherently reasonable.

The rapid expansion of the science that can support improved rational medical decision making is one of many stressors on the medical education system in the United States. However, it is difficult to escape the conclusion that medical education and the practice of medicine are distancing themselves from rigorous training in the biomedical sciences and the skill sets necessary to apply this science clinically in a rational manner. Medical schools are challenged to incorporate new biomedical knowledge into limited curricula time using an ever-increasing number of faculty for whom medical education is not the highest priority. Important additional competencies ${ }^{3}$ relevant to the practice of medicine are competing with the teaching of core scientific knowledge for student time. In US medical schools between the 1993-1994 and 2003-2004 academic years the mean number of scheduled curriculum time in years one and two fell by 100 hours $^{4}$. The level of detail at which the basic sciences need be taught for clinical practice has been challenged by students and clinicians. During preclinical courses students too often perceive biomedical sciences as not being "relevant" to clinical care ${ }^{5-7}$. This in part reflects curricula failing to devote adequate time and effort to impart upon students a true understanding of the science and link it to a sophisticated approach to thinking in the clinical setting.

The paradox of an insufficient focus on the scientific basis underlying medical practice in the teaching of medicine is particularly evident during clinical rotations at many medical centers. Clinical faculty encountered by many trainees are generally well-trained and highly skilled physicians, but are not uniformly conversant with the scientific foundations of medicine. As a result, their approach to medical practice does not adequately role model the value of science in decision making, thereby implicitly sending the message that such knowledge is clinically irrelevant. Students are quick to pick up this message, further reinforcing their ambivalence about learning the science that underlies the practice of medicine.

In response to these pressures, reformers of medical education now argue (without refuting its value) that the Flexner Report's model of the academic clinician applying science at the bed side is no longer practical ${ }^{8}$. Financial and academic accountability of faculty have made it challenging to 
integrate the traditionally academic faculty with the clinical faculty delivering the bulk of patient care and clinical teaching. One discussion of increased trainee interactions with this clinical faculty cites the lessons of cognitive psychology and emphasizes the importance of experiential learning in which core concepts are applied ${ }^{8}$. However, the irony of omitting basic science principles from the constellation of skills that require experiential reinforcement often seems lost on advocates for these changes and the students who perceive only the resultant discontinuity in their education. Increasing emphasis on apprenticeship-based education ${ }^{8}$ and increased focus on the non-medical knowledge competencies ${ }^{9-12}$ inevitably will be at the expense of rigorous training in the basic sciences if the existing number of hours available for teaching are maintained. The result may be that basic science teaching is being compromised without explicit assessment, and only limited discussion of the consequences.

The United States Medical Licensure Examination (USMLE) is re-evaluating the medical licensure exam for the United States ${ }^{13,14}$. A committee charged with reviewing the USMLE has recommended that the process focus on patient-centered training decision points, one relevant to supervised practice (residency) and one for unsupervised practice (independent practice ${ }^{13,14}$. A possible consequence of this revised structure is the removal of the existing science-centric Step I exam. At many medical schools this could eliminate one driver for a broad-based, science-rich, medical curriculum. While the recommendations for revision of the USMLE call for inclusion of basic sciences at both decision points, emphasis would be placed on science that is relevant to actual medical practice. This may be a reasonable proposition, but who will judge the science content that is relevant to medical practice-clinicians who currently dominate clinical teaching or academic physicians with broad insight into the scientific foundations of practice? In the modern context, learning biomedical science relevant to the practice of medicine does not mean the rote memorization of details such as multi-protein signaling cascades or other similar information. Rather, the physician must conceptually understand the pathway (or other process) and know when it is clinically important to know the details. The physician then must know how to rapidly access the details (if not known) and apply this knowledge and understanding to improved decision making for an individual patient.

The growth in the use of critical pathways and other algorithm-based approaches in clinical care add additional paradoxes to the educational structure. These algorithms are often "evidence-based" and thus "scientific" in their development. Furthermore, they often have demonstrated ability to improve the efficiency of care and decrease systems-based errors on a population basis. But what role should the physician play in this algorithm-driven healthcare delivery model? For a health care practitioner (physician or otherwise) to simply follow the pathway and thereby deliver "evidencebased care" requires no high level cognitive skills; indeed, nonphysicians can function at equivalent or superior levels based solely on algorithm compliance ${ }^{15,16}$. Rather, it is reasonable to posit that the physician's responsibility is to be a critical thinker who can recognize when the algorithm should not be rigidly implemented based on the unique features of an individual patient and play an "over-ride" function. The physician's imperative is the care of his or her patient, not the population that forms the basis of the probability-driven guidelines.
Care for patients whose clinical status mandates a deviation from the standard algorithm requires a higher level of insight and rigor of analysis and decision making, and increases the training requirement for physicians. Thus, training centered only on the most common clinical presentations or problems cannot achieve this higher goal. Should medical education be designed to train doctors to deal with the vast majority of cases where the role of a physician is that of passive implementer of care, or should training give special attention to those cases requiring their expertise, insight and cognitive skills? If the goal is only the former, then it is difficult to justify the current level of educational rigor and commensurate financial compensation for physicians. Confronted with a challenging clinical problem or novel decision tree it is reasonable to posit that understanding of the underlying biology, pathophysiology or pharmacology will result in a more logical and reasoned resolution. Further, research supports the hypothesis that basic science knowledge is an asset to clinical decision making. Integrating relevant basic science mechanisms to the teaching of disease has the potential to improve retention and diagnostic application of the information ${ }^{17-19}$. Importantly, as noted by Woods and colleagues ${ }^{17}$, this utility is likely based on "deeper causual connections between signs and symptoms and not on superficial representations." Thus, the clinical utility of the basic sciences is not solely dependent on recall of specific facts which may have limited retention ${ }^{20}$, but also on the ability to develop functional insights and connections based on scientific foundations. Clearly strategies to optimally teach students this material, including integration of new developments in learning theory, to maximize translation of knowledge into improved clinical decision-making are of critical importance.

Ironically, while discussed to some degree in the medical literature $^{21,22}$, concern about the potential loss of scientific reasoning and intellectual curiosity amongst clinicians may currently be highlighted more in the lay press than the academic literature. In his review of Jerome Groopman's book "How Doctors Think" ${ }^{23}$ Michael Crichton points out that "Today's physicians are increasingly encouraged to...reason through flowcharts and algorithms...This approach can be useful for 'run-of-the-mill' diagnosis and treatment...but for difficult cases...it is limiting and dehumanizing". ${ }^{24}$ Susan Love in an editorial on medical research notes "The curious clinician is becoming increasingly rare. Medicine and science have become so complicated that it is almost impossible for one person to be expert at both" ${ }^{25}$. Thus, the devaluation of the scientific foundations of medicine and medical practice may fail a test of face-validity and over time will likely result in a loss of public confidence and respect for physicians.

The current shortage of clinician scientists ${ }^{26-28}$ may be exacerbated as an unintended consequence of failure to maintain robust biomedical science content in medical curricula. An understanding of biomedical science and the promises it holds for improving health care are powerful motivators in inspiring medical students to pursue research careers. Exposure to role models during training, both physician-scientists and physician-educators, who illustrate the integration of science and clinical practice are important for motivating trainee investment in research training. It has been suggested that the current shortage of trained investigators has compromised the translation of new basic discoveries to effective therapeutics ${ }^{27}$. Dilution of scientific rigor during medical school will likely worsen this problem. 
What does the loss of scientific rigor and intellectual curiosity in medical education have to do with internal medicine? The past 20 years have witnessed a decrease in the quantity and quality of United States medical school graduates pursing careers in internal medicine ${ }^{29,30}$. There are clearly multiple reasons, including financial, for the decreased popularity of internal medicine as a career choice by United States graduates ${ }^{30,31}$. Nonetheless, the positive aspects of a career in the specialty may be increasingly obscured. The opportunity to develop substantive, longitudinal relationships with patients while meaningfully contributing to the quality of their lives is integral to the discipline. At the same time, the personal, intellectual satisfaction derived from successfully solving a diagnostic dilemma is part of the internist's reward system. Integration of available data to formulate a successful, and perhaps novel, management plan is a source of pride within the specialty. While a strong foundation in the basic biomedical sciences is only one strategy for evoking intellectual curiosity in trainees, when medical education fails to foster such curiosity or the excitement from solving a difficult clinical problem the intangible satisfactions of a career in internal medicine are obscured. When training during and after medical school fails to provide trainees with the tools to reason through a diagnostic challenge, and when the educational experience fails to provide clinical role models with these skills, students will fail to visualize the opportunities for themselves in the specialty. Medical schools continue to attract some of the brightest young people in the country. These students can recognize that their personal and professional quality of life may be better served through specialties other than internal medicine. Reinvigorating the intellectual rigor in medical education and internal medicine training is needed to engage these students.

Medical school education in the United States is facing enormous challenges. Thoughtful re-examination of the assumptions and tenets underlying the current structure, timing and content of the medical school curriculum is important, and reform and transformation of the system may be necessary. Nonetheless, the risks as well as the benefits of any changes must be understood. De-emphasizing basic biomedical sciences and their importance in clinical decision making may facilitate the teaching of previously neglected clinical competencies ${ }^{3}$, achieve a number of short term efficiencies and perhaps even improve performance on a number of process-oriented metrics. However, if such achievements occur at the expense of the unique cognitive skills historically integral to the profession, and in particular to internal medicine, the specialty and society may be the poorer. To meet the increasing demands on medical education, including the teaching of biomedical sciences, radical reform may be needed in the financing of medical education (from both faculty and students perspectives) and the time required to complete medical school training. For example, Dienstag has suggested shifting some of the scientific curriculum from medical to undergraduate course work to allow more focus on the application of this material within the restrictions of the current medical school time lines ${ }^{32}$. As we face the challenge of dealing with an expanding basic science knowledge base and the teaching of additional competencies, the existing 4-year (or less) medical school can simply not accommodate all requirements. The wrong solution is to reduce traditional necessary core material to accommodate new core material. The debate is what is necessary, what needs to be taught in the medical school vs. post-graduate curricula, and what broader restructuring may be required to accommodate the new educational requirements.

Internal medicine has much at stake if the traditional integration of the cognitive and humanistic skills of the specialty are lost. The specialty should be engaged in the medical education debate and provide a strong voice supporting the intellectual foundations of our profession.

Acknowledgments: The author thanks Drs. P. Insel, R. Glew. R. Feldman and T. Smith for many insightful discussions and their comments on this manuscript.

Conflict of Interest: None disclosed.

Corresponding Author: Eric P. Brass, MD, PhD; Department of Medicine, Harbor-UCLA Medical Center and the David Geffen School of Medicine at UCLA, 1124 W. Carson Street, Torrance, CA 90502, USA (e-mail: ebrass@ucla.edu).

\section{REFERENCES}

1. Flexner A. Medical education in the United States and Canada. New York 1910.

2. Starr P. The social transformation of American medicine. 1982.

3. ACGME. ACGME Outcomes Project - General Competencies. http:// www.acgme.org/outcome/comp/compMin.asp. Accessed April 13, 2009, 2009.

4. Barzansky B, Etzel SI. Educational programs in US medical schools, 2003-2004. JAMA. 2004;2929:1025-31.

5. West M, Mennin SP, Kaufman A, Galey W. Medical students' attitudes toward basic sciences: influence of a primary care curriculum. Med Educ. 1982;164:188-91.

6. Custers EJ, Cate OT. Medical students' attitudes towards and perception of the basic sciences: a comparison between students in the old and the new curriculum at the University Medical Center Utrecht, The Netherlands. Med Educ. 2002;3612:1142-50.

7. Custers EJ, Ten Cate OT. Medical clerks' attitudes towards the basic sciences: a longitudinal and a cross-sectional comparison between students in a conventional and an innovative curriculum. Med Teach. 2007;298:772-7.

8. Cooke M, Irby DM, Sullivan W, Ludmerer KM. American medical education 100 years after the Flexner report. N Engl J Med. 2006;355 (13): 1339-44

9. Delzell JE Jr, Ringdahl EN, Kruse RL. The ACGME core competencies: a national survey of family medicine program directors. Fam Med. 2005;37(8):576-80

10. Litzelman DK, Cottingham AH. The new formal competency-based curriculum and informal curriculum at Indiana University School of Medicine: overview and five-year analysis. Acad Med. 2007;82(4):41021

11. Ogrinc G, Headrick LA, Mutha S, Coleman MT, O'Donnell J, Miles PV. A framework for teaching medical students and residents about practicebased learning and improvement, synthesized from a literature review. Acad Med. 2003;78(7):748-56.

12. University of Wisconsin School of Medicine and Public Health Innovations in Medical Education. http://ime.med.wisc.edu/curriculumGoals. php. Accessed April 13, 2009.

13. USMLE Moves to Next Step to Design Review. http://www.usmle.org/ General_Information/review.html. Accessed April 13, 2009.

14. Committee to Evaluate the USMLE Program. Comprehesive Review of USMLE. http://www.usmle.org/General_Information/CEUP-SummaryReport-June2008.PDF. Accessed JApril 13, 2009.

15. Ohman-Strickland PA, Orzano AJ, Hudson Sv, et al. Quality of diabetes care in family medicine practices: influence of nurse-practitioners and physician's assistants. Ann Fam Med. 2008;6(1):14-22.

16. Becker DM, Raqueno JV, Yook RM, et al. Nurse-mediated cholesterol management compared with enhanced primary care in siblings of 
individuals with premature coronary disease. Arch Intern Med. 1998;158(14): 1533-9.

17. Woods NN, Brooks LR, Norman GR. The role of biomedical knowledge in diagnosis of difficult clinical cases. Adv Health Sci Educ Theory Pract. 2007;12(4):417-26.

18. Woods NN, Brooks LR, Norman GR. It all make sense: biomedical knowledge, causal connections and memory in the novice diagnostician. Adv Health Sci Educ Theory Pract. 2007;12(4):405-15.

19. Woods NN, Neville AJ, Levinson AJ, Howey EH, Oczkowski WJ, Norman GR. The value of basic science in clinical diagnosis. Acad Med 2006;81(10):S124-7.

20. Custers EJ. Long-term retention of basic science knowledge: a review study. Adv Health Sci Educ Theory Pract. Feb 152008.

21. Ausiello D. Science education and communication: AAP Presidential Address. J Clin Invest. 2007;117(10):3128-30.

22. Wortmann RL. The clinical philosophy of internal medicine. Am J Med. 1998;104(4):323-6.

23. Groopman J. How doctors think. New York, New York: Houghton Mifflin; 2007.

24. Crichton M. Where Does it Hurt. New York Times. April 1, 2007.
25. Love S. To Break the Disease, Break the Mold. New York Times. April 1, 2007.

26. Mark AL, Kelch RP. Clinician scientist training program: a proposal for training medical students in clinical research. J Investig Med. 2001;49 (6):486-90.

27. Sung NS, Crowley WF Jr, Genel M, et al. Central challenges facing the national clinical research enterprise. JAMA. 2003;289(10):1278-87.

28. Nathan DG. Careers in translational clinical research-historical perspectives, future challenges. JAMA. 2002;287(18):2424-7.

29. National Resident Match Program Historical Reports. http://www. nrmp.org/data/historicalreports.html\#resultsbystate. Accessed April 8 , 2009.

30. Singer N. For Top Medical Students, an Attractive Field. New York Times. March 19, 2008, 2008.

31. Newton DA, Grayson MS, Thompson LF. The variable influence of lifestyle and income on medical students' career specialty choices: data from two U.S. medical schools, 1998-2004. Acad Med. 2005;80(9):80914.

32. Dienstag JL. Relevance and rigor in premedical education. N Engl J Med. 2008;359(3):221-4. 